\title{
Anonymity and authenticity on the web
}

\section{Towards a new framework in internet onomastics}

\author{
Saskia Kersten and Netaya Lotze \\ University of Hertfordshire | University of Münster
}

\begin{abstract}
Building on our own research (Kersten and Lotze 2018; Kersten and Lotze 2020; Lotze and Kersten (in press); Lotze and Kersten (under review)) as well as other work in this area (BecharIsraeli 1995; Stommel 2007; Lindholm 2013; Aleksiejuk 2016a, 2016b), this article will discuss the pragmatics of (self-)naming practices online and how they contribute to identity construction and face-work (Bedijs, Held and Maßß 2014; Seargeant and Tagg 2014). Drawing on the data collected, both existing and analysed as part of a wider study of usernames across 14 languages (Schlobinski and Siever 2018a), the use and function of anthroponyms and other names in online contexts are explored. Furthermore, we endeavour to situate both onomastic- and sociolinguistic research in the field of digitally-mediated interaction (DMI) and in the field of pragmatics in general.
\end{abstract}

Keywords: user names, handles, self-naming, internet onomastics, onomastics, online practices, authenticity, anonymity, face work

\section{Address for correspondence}

Saskia Kersten

University of Hertfordshire

School of Humanities

Hatfield

Hertfordshire

AL10 9AB

United Kingdom

s.kersten@herts.ac.uk

Netaya Lotze

Westfälische Wilhelms-Universität

Germanistisches Institut

Abteilung Sprachwissenschaft

Schloßplatz 34

48143 Münster (Germany)

lotze@uni-muenster.de 


\section{Introduction}

Thinking about formality and informality in connection with naming practices online raises an interesting point: Can formality and informality be clearly delineated in this context? In the following, we argue that whether username choice could be regarded as formal or informal is to a high degree dependent on context (cf. Section 4.2). Furthermore, the delineation of communicative contexts as formal or informal is likewise not without challenges, not least because for the user the contexts in which their usernames will be perceived are ultimately unknowable due to context collapse (boyd and Marwick 2011). We suggest instead that online self-naming practices can be viewed in terms of proximity and distance in relation to others, be it groups or individuals, and outline a framework for analysing usernames along this cline as well as societal conventions and group conventions. This, at first glance at least, appears to be in opposition to the clearly drawn line between formal, authentic legal names on the one hand and informal nicknames on the other. In our analysis of data collected as part of a large scale project of usernames (Schlobinski and Siever 2018a), it becomes evident that usernames cannot be neatly categorised as being one or the other because many users choose to employ at least a certain degree of hybridity while striving to reconcile conflicting goals, namely the need to authenticate oneself and the desire to preserve at least a degree of anonymity (see also Kersten and Lotze 2020; Lotze and Kersten in press).

We furthermore argue that username choice is an inherent part of online face-work. Although there are several contributions that look at face-work in digitally-mediated communication (e.g., Bedijs, Held and Maaß 2014), few focus solely or predominantly on usernames, even though, as Aleksiejuk (2016a: 3) argues, they are "an important element of the study of computer-mediated communication." If usernames and (self-)naming strategies are mentioned in studies, they are usually only one of many aspects that are analysed, a gap which this present article is hoping to fill.

As previous research has discussed, Goffman's ideas of frontstage and backstage are useful constructs to contemplate; however, in online contexts, the boundary between the two has become increasingly blurred (see e.g., Shulman 2017). We argue that levels of formality and informality play a role in usernames in a number of different ways: alignment with an in-group by formally accepting (potentially implicit) username conventions, explicit and expected username conventions imposed on users by the respective platform and informality by rejecting or undermining these conventions in a number of ways to cloak one's identity. 
Furthermore, formality can be emergent, since naming conventions evolve over time (see e.g., Lindholm 2013 for a discussion of, amongst others, username threads on Mumsnet) and users employ new semiotic resources that may not be as easily separated into formality and informality, for example, emoji use when it becomes conventionalised (see e.g., Beißwenger and Pappert 2019 on face-work with emojis).

That usernames play an important role in digitally-mediated interaction (DMI) is exemplified by the stir a recent change on the Instagram account of the Duke and Duchess of Cambridge, William and Kate, caused. Although their handle, that is, the actual username, remained the same (@KensingtonRoyal), the fact that they chose to change the name displayed at the top of the account from Kensington Royal to The Duke and Duchess of Cambridge was widely applauded (see e.g., Bonner 2020 in Cosmopolitan). According to the Mail Online, this was the first time in five years the display name was changed and fans are cited as stating that it makes it 'feel more personal' (Morgan 2020); this could be argued to be a shift from a more formal to a less formal (and thus more personal) display name in the eyes of the followers.

The discussion of how people strive to resolve the tension between preserving their anonymity while at the same time constructing a recognisable (and increasingly memorable) identity online is not new (see e.g., Barton and Lee 2013; Tagg 2015). The notion that interaction on social media involves face-work has likewise been discussed (see e.g., Bedijs, Held and Maßß 2014). This article aims to extend these discussions to usernames and username choices and argues that names and self-naming practices are also an explicit part of face-work, as we have done in previous publications (Kersten and Lotze 2018, 2019; Lotze and Kersten under review; for a detailed discussion see Section 4). In addition to this and in the spirit of the theme of this special issue, it focuses on the role formality and informality play in this context.

\section{The Nicknamen International ('international usernames') study}

The data used to illustrate our discussion of formality and informality in relation to usernames predominantly draws on our previous work on usernames which was part of the Nicknamen International project (Schlobinski and Siever 2018a) that investigated usernames in 14 languages.

All researchers involved in this project followed the same data collection procedure. 500 usernames were sampled in total: 100 each from Flickr, Twitter, a TV show forum, an IT forum and below-the-line comments from the politics and current affairs pages of a tabloid 
newspaper; ${ }^{1}$ although the sources of the data had to be adapted to the local context where necessary.

The detailed analysis of the collected usernames for all 14 languages was conducted using an online platform that utilised a tag set developed specifically for the Nicknamen International project and included onomastic, orthographic, morphological, phonological, lexical, syntactic and semantic categories (Schlobinski and Siever 2018b: 18). ${ }^{2}$ This approach ensured comparability across the languages analysed. In addition to the quantitative analysis of the usernames, some project groups also collected data using questionnaires ${ }^{3}$ (Kersten and Lotze 2018: 119-121; see also Section 5 for a more detailed discussion).

The analysis of the English language data (Kersten and Lotze 2018), which focused on usernames in UK contexts (although usernames from other varieties of English were not explicitly excluded), showed that more than half (275 out of 500) of the usernames analysed included some form of name that could be regarded part of the onymic inventory of English (see also Figure 1). This could take the form of first names, for example, in the Twitter handle of the novelist Joanna Harris @joannachocolat (50.8\%), or last names, for example, in the Twitter handle of Labour MP Chris Bryant @RhonddaBryant (35.6\%). When first names were included, this was often in hypocoristic form (23.6\%), for example, Eddie instead of Edward (as in wee eddie); initials were much less frequently included (3.8\%). Hypocoristic forms of last names, for example, buzzer 999 , the username of someone whose last name included the syllable bus, were rare (2.0\%), even though $35.6 \%$ of usernames in the corpus contained last names or parts thereof. An interesting observation relevant for the discussion of formality and informality is that, although it is common in the UK to have more than one first name, usernames rarely included more than one first name or parts thereof. Furthermore, as can be seen in the above examples, usernames often include other words in addition to the onymic element which may be included to make the username more readily recognisable, for example, the inclusion of the title of her well-known novel in @joannachocolat or the name of the constituency in@RhonddaBryant.

\footnotetext{
${ }^{1}$ These platforms were chosen to create a sample of different groups of users and contexts: while Flickr is a topicand context-oriented community comprised of professional and amateur photographers, Twitter does not have a specific topic focus. TV commentaries are predominantly ad hoc commentaries by individuals who watched the same show without necessarily being particularly group-oriented. The IT forum threads are topic-focused and contain both users that know each other and therefore may form a Community of Practice as well as one-off users who just seek help for a particular technical problem.

${ }^{2}$ A screenshot of the online interface used to analyse the usernames can also be found on mediensprache.net: https://www.mediensprache.net/de/websprache/pubs/7/ (accessed 6 July 2020; in German only).

${ }^{3}$ The ethics protocol number for this data collection is EDU/SF/UH/02698.
} 
Number of usernames in our study containing a... $(n=500)$

...first name

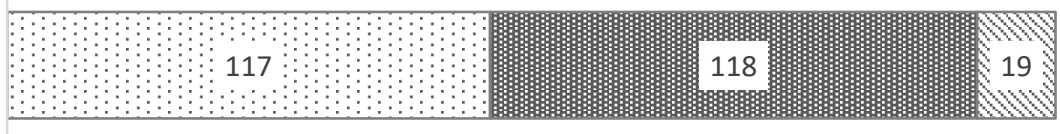

...middle

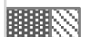

name

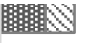

...surname

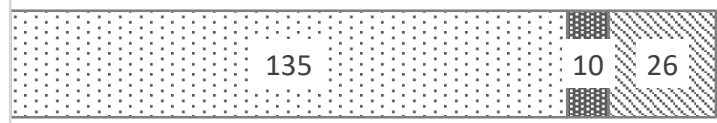

0

50

100

150

200

250

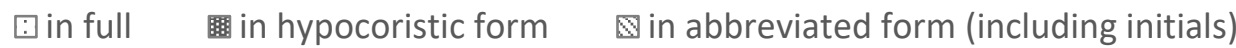

Figure 1. Types of names included in the 500 usernames analysed (cf. Kersten and Lotze 2018)

Since social media platforms enforce mono-referentiality, that is, each username must be unique, a number of strategies could be observed that are employed to achieve this, for example, the inclusion of numbers (19\%; I need help! 22; Perseus1). Even though a recent Lifewire article on How to Create the Perfect Screen/Username (De Hoyos 2020) tells readers to consider "substituting symbols and letters that are similar: $@=a, 3=e, \$=5, S=5$ ", a strategy sometimes also known as leet or Leetspeak, this was exceedingly rare in our data. This could be because Leetspeak is a relatively dated strategy that was typical of a particular group of internet users and a particular time in internet history and can be interpreted to be a conventionalised, and therefore at least to a degree formal, strategy that has fallen out of favour and has been superseded by other strategies outlined in more detail below.

Another platform-induced strategy that could be observed in the data is that because some platforms (e.g. Twitter) do not allow the use of spaces in usernames, word boundaries were demarcated in a number of different ways, for example, by including an underscore (Salad_Days104). Another, much less common way to mark word boundaries is to use capitalisation but whether this strategy is available is subject to the constraints of the social media platform. The use of an underscore can therefore be argued to be a formally established, and thus well-known, strategy.

In terms of lexical categories, the explicit use of dialectal material was again rare (e.g. wee eddie, Getawaywitya), even though there is generally an increased visibility of the vernacular/non-standard in online spaces (Barton and Lee 2013: 15ff). There was also almost 
no inclusion of swearwords in usernames which again may be traced back to username policies of the respective platforms as well as the fact that, for example, newspaper forums often have moderators that delete inappropriate or offensive comments, which may include posts by usernames incorporating certain words (see also Androutsopoulos 2015 on the effect of moderators on DMI). There was, however, a preference for certain usernames that clearly depended on the communicative context and Community of Practice (CoP; for a more detailed discussion, see Section 3 below), often in the form of contextually relevant appellatives; for example, many usernames used on Flickr included references to cameras and/or photography (badcampix; E300 DSLR), whereas in the IT forum some usernames included references to what the user was seeking information on or help for (tomtomfrustrated).

Following the Nicknamen International project, we have previously discussed usernames as an act of self-naming from a predominantly onomastic perspective (Lotze and Kersten 2020), the creation of a self-image online from an applied linguistic perspective (Kersten and Lotze 2019) as well as the methodological approach to username research (Lotze and Kersten under review). The present article builds on these discussions as it adds a new angle to the data and outlines a framework for the interpretation of username data along a number of clines of which the formality - informality cline is one, but which also includes more abstract dimensions. The focus in the following is on the role the notion of formality and informality play in (self)-naming, but first an overview of previous research on usernames is given in the following section.

\section{Usernames and self-naming practices online}

This section gives an overview of studies that have investigated self-naming practices online, drawing on a number of disciplines. In addition to applied linguistics, and more specifically onomastics, researchers from psychology and media studies have also investigated usernames and the driving factors behind them using a range of methodologies. Socio-onomastics is a relatively new area of interest (see Aleksiejuk 2016b on usernames; Ainiala and Östman 2017 on socio-onomastic in general).

Naming is almost always an expression of power, not least because normally a person is named rather than naming themselves: 
The act of naming is an act of power. Parents naming children, conquerors naming new lands, and organizations naming themselves all involve the assertion of authority and control. Names allow us to communicate through the development of shared meanings. (Guenther 2009: 412)

Username choice could therefore be regarded as being particularly powerful, because, just like organisations naming themselves, here the individual chooses their own name. This choice, however, may still be constraint by a number of factors (see Section 2 above).

One aspect of usernames that has been investigated quite widely is that of gender. In particular the absence of information on gender has been a main focus of scholarly interest, although Herring and Stoerger (2014) report that the language produced in chats does contain cues that 'reveal' the gender of the interlocutor (Herring and Stoerger 2014) and usernames also often contain information that allows others to either deduce or at the very least make educated guesses about the gender of the person behind the mask. The fact that many interactants and researchers at least partially rely on usernames to infer gender is hence well documented (Rodino 1997; Del-Teso-Craviotto 2008; Kapidzic and Herring 2011; Herring and Stoerger 2014).

While some languages do have an onymic inventory that is gendered (what Subrahmanyam, Greenfield and Tynes 2004 in an otherwise highly problematic study [for a critical discussion, see Aleksiejuk 2016a] refer to as 'accepted male/female names'), this is not always the case. Del-Teso-Craviotto (2008), for example, observed that while usernames in Spanish-language dating chats often indicated gender by consisting of or including gendered given names as well as grammatically female appellatives in the form of nouns and adjectives, this was not the case in the English language chat rooms, for the obvious reasons that grammatical gender is negligible in appellatives and, although gendered first names exist, there are also many onyms that can be used by any gender, such as Kiran, Riley or Jules; the Dictionary of First Names compiled by Hanks, Hardcastle and Hodges (2003), for example, includes a list of 203 so-called unisex names.

In predominantly quantitative studies, usernames are typically collected and classified using a set of categories. One of the earliest ones that other studies often emulate or build on is that by Bechar-Israeli (1995) who categorised usernames used in internet relay chats (IRCs) into 14 different categories based on semantic, functional and formal (e.g., orthographic) features; the categories overlapped to some extent and were not mutually exclusive. A range 
of other studies follow this approach by either adopting (and in some cases adapting) BecharIsraeli's (1995) classification system (e.g., Scheidt 2001; Lev and Lewinsky 2004; Martin 2013), while others use a different classification system altogether (e.g., Ráatz 2011; Hämäläinen 2013; Olivier 2014) or in addition to the one developed by Bechar-Israeli (e.g., Hassa 2012; Lindholm 2013; Kaziaba 2016; Schlobinski and Siever 2018a).

In addition to the quantitative classification of usernames, many studies investigate the motivation behind the choice of usernames, particularly because a classification purely based on the names themselves can at times be difficult if there is no background knowledge available to the researcher that can be used to disambiguate and interpret the usernames (see e.g., Hagström 2008, 2012).

Other studies that investigated the motivation behind usernames in a number of different ways are, for example, Aldrin (2019) who interviewed four teenagers about the nicknames they use when interacting while using mobile phones as part of a pilot study and Del-Teso-Craviotto (2008) who analysed interactions in dating chat rooms, including the use of, and reaction to, usernames. Kelley (2012) analysed the usernames used in LGBT gaming guilds and found that many references to, for example, rainbows and other related terms that are generally associated with LGBTQ+ spaces and the incorporation of symbols associated with LGBTQ+ communities could be regarded as constituting a formal way of signalling group membership. Others, however, deliberately reject this and are reported as "preferring a guild that is not "named with neon letters' nor 'so visibly gay" (Kelley 2012: 198), thus diverging from (perceived) conventialised guild naming conventions. Kelley concludes that "gay naming in online gaming may not be all that different from gay naming in the so-called real world, where one finds a similar tendency for organizational names to conceal nearly as much as they reveal" (2012: 199). This quote links back to the tension between recognisability (and thus authentication) and preservation of anonymity (or least relative obscurity) that is one of the central aspects of self-naming online (see Sections 1 above and 4 below) and can be interpretated as a tension between the desire to adhere to formalised naming conventions and the desire to express individuality.

Since the interpretation of usernames is most successful if there is some kind of context information or information on the motivation behind the username choice available, it is not surprising that a majority of studies employ a mixed methods approach combining qualitative and quantitative methods (see also Lotze and Kersten under review for a discussion of methods used in internet onomastics). 
Since name choice and self-naming are both highly complex processes involving a number of conscious choices that require not only the adherence to platform-specific constraints but also group-specific conventions that users may align their usernames with to signal that they are (or aspire to be) a member of a group (which in turn can be interpreted as adhering to expected and therefore formal naming conventions), a range of methodologies have been employed to investigate these phenomena in all its complexity. The most common tools employed are questionnaires to shed light on the motivation behind username choices (e.g., the contributions to the Nicknamen International project [Schlobinski and Siever 2018a]; Kaziaba 2016), interviews (Hagström 2008, 2012) or by analysing forum threads in which users explicitly discuss their usernames and the meaning(s) behind them (e.g., Lindholm 2013). Using online ethnography, Gatson (2011) utilised username lists as well as her own knowledge of a particular fandom, namely Buffy the Vampire Slayer and the associated fan site The Bronze, in both online and offline contexts, reporting a number of anecdotes how users arrived at their usernames, how these sometimes even extend to their partners and the way they bleed into 'real life' interaction.

The other side of the interaction, namely the perception of usernames by interlocutors, has predominantly been investigated using experimental studies, commonly undertaken by psychologists. Heisler and Crabill (2006), for example, asked their participants to rate six fictional email addresses along a number of categories. Their results showed that participants will at least try to ascribe features such as gender, ethnicity and some character traits to the people they assume are lurking behind the 'mask'. Several other studies use the Big Five Inventory of character traits to investigate the perception of usernames from World of Warcraft, among others (see e.g., Graham and Gosling 2012; Lange et al. 2019).

From a more linguistic perspective, Hämäläinen (2013: 228) investigated what constitutes a 'good' username by first compiling and analysing a list of usernames from the online gaming platform Playforia. In a second step, he used Likert scale data and a questionnaire asking informants to rank usernames in terms of "how 'good' they are" (Hämäläinen 2013: 228) and then deduced similarities between the usernames that ranked highly. He concluded that 'good' usernames appear to be the ones that start with a capital, do not contain neither many (or any) special characters nor apparently meaningless numbers. Informants also overwhelmingly preferred 'mysterious,' that is, complicated, not easily deducible usernames, which may be a result of the alignment with a $\mathrm{CoP}$ on this particular platform, since this is a finding that is not always echoed in other contexts. Although the respondents in Heisler and Crabill's (2006: 128) 
study generally preferred creative email addresses over plain ones, they also appeared to be wary of those that remain opaque, since "this could be anyone" as one respondent stated.

In addition to this, it has been observed that usernames are highly dependent on the desire to implicitly or explicitly signal group membership. In forums in which users post and answer tech questions, usernames often contain information on the nature of the gadget (e.g., tomtomfrustrated; Kersten and Lotze 2018), in parenting forums people agonise over whether they should change their usernames after having another child (motheroffour; Lindholm 2013). Stommel (2007) observed that usernames used in anorexia forums often connote smallness or lightness/weightlessness.

On dating sites, Spanish speakers use username cues to guess the gender of their interlocutors (e.g., Del-Teso-Craviotto 2008 recounts how a user with a username that is perceived to be male is asked to leave a particular forum aimed at lesbians over 30). The usernames in dating forums have also been shown to encode the traditional 'sex-age-location schema' that used to be a common feature of classified ads (Del-Teso-Craviotto 2008), a formal convention that aids the rather formulaic communication of certain facets of one's identity and can be regarded as an example of formality that has successfully migrated from one communicative context to the next.

As a result of this frequently observed alignment with specific group conventions, it can be concluded that username choice is a conscious process that is designed to give interactants clues as to the identity of the person behind the username. This disclosure may only be partial, since users curate a tailor-made identity that can also vary from platform to platform (although some deliberately choose to use the same username on different outlets to create a cohesive and seamless online presence). A username can thus be viewed to be a mask in the Goffmanian (1955) sense and is therefore an important part of online face-work (Kersten and Lotze 2019). The degree to which usernames either converge with or diverge from implicit and explicit username conventions can also be seen as being on a formal-informal cline. This aspect of usernames is explored in more detail in the following sections.

\section{Self-naming as a sociolinguistic practice: An attempt at a definition}

The guiding questions for this section are: To what extent can the results from our international study on usernames and the studies discussed in Section 3 be interpreted in the light of the digital revolution, the associated shifts in private and public spheres and the focus of this special issue, namely formality and informality? And to what extent can a theory of self-naming 
online be integrated into more recent approaches to the analysis of newly emerging online conventions, new styles and genres?

\subsection{Formality and informality in online styles}

In the following, we discuss self-naming online as an element within the wider field of online styles from a variationist perspective to shed light on the conditions of use of digital communication from a micro-diachronic perspective.

Linguistic and multimodal style variation in DMI are highly community-specific. On a socio-pragmatic level, this means that sociolinguistic online practices are as diverse and multimodal as user groups are heterogeneous.

In terms of structure and style, the members of online communities interactively and dynamically develop new linguistic variations (e.g., through interactive alignment, see Pickering and Garrod 2004) that - like all neologisms and new structures - are either shortlived or evolve into a group-specific standard that may then evolve into a more general standard adopted widely in the language community (e.g., Kooti et al. 2012).

Because of the possibilities of real time mobile and multimodal communication, the digital revolution has led to many processes of linguistic change simultaneously that diachronic linguistics has only just begun to describe. Reasons for this are, among others, the de-situation (Luhmann 1984) of face-to-face oral communication with the advent of telecommunication generally and social media more recently which allows for synchronous written exchanges. This has led to the emergence of 'new literacies' (Androutsopoulos 2007) and the use of new semiotic resources, for example, pictures and emojis. New style features are the result of a changed and changing highly complex mediatization which is still in its early stages and whose linguistic conventions are still in the process of forming. Consequently, to attempt to systematically describe the changed and changing initial conditions and contexts that lead to formal and informal styles, for which traditional classifications of genre and text type are no longer appropriate, is an ambitious endeavour.

The digital revolution has led to a global and mobile de-situating of communication, while also making communication that used to be ephemeral more permanent and persistent. The increased range of interaction and the fact it can (and will!) now be stored indefinitely generate novel communicative situations in which the privacy of users is threatened in two ways: (1) by a (partial) public who can now read formerly private communication and (2) by the large-scale data storage and analysis of this communication by Silicon Valley corporations that provide 
the only data infrastructure available. For the user, this blurring of private and public spheres results in a dilemma between a desire for social encounters on the one hand and the protection of privacy on the other (cf. Bedijs, Held and Maaß 2014; see also Kersten and Lotze 2019). Addressing this dilemma results in a new form of face-work in the Goffmanian (1955) sense: How do we communicate appropriately with regard to formality levels when an unknown and unknowable public is always reading along? This is the result of a number of different factors. 'Context collapse' means that the content creator does not know who ultimately will read the content while the participatory culture on social media additionally constantly reshapes and reimagines content in the form of, for example, quoted tweets and memes. Another level of 'context collapse' is the fact that the content itself has been modified by Sillicon Valley companies which routinely mine all user-generated content for data, including usernames.

Against this background, new genres with new stylistic characteristics are rapidly developing (see Marx and Weidacher 2014). Both traditional registers and the associated text types and genres form a framework as well as new group- or platform-specific conventions, for example, in influencer marketing, which emulates traditional elements of public communication using the language of advertising (e.g., slogans, words that are associated with prestige, descriptive adjectives; see Marx and Lotze 2019).

If the early studies on DMI were primarily empirical individual studies, the theory formation on formal and informal online styles is now at an advanced level: Typical structural and functional features of these newly forming styles can be interpreted against the backdrop of a theory of Communities of Practice (Lave and Wenger 1991) as group-specific face-work in the Goffmanian sense (1955) (for a discussion of CoPs in DMI, see Angouri 2015). Because of the tension between privacy and public reach that is ever prevalent in social media, the curated self-image is of unprecedented relevance. Since a clear definition of the target audience of online communicates is no longer possible because of potential de-contextualization and recontextualization (e.g., in the form of retweets or memes, Seargeant and Tagg 2014: 8) contexts also collapse at the level of relational work with other users. Consequently, creating a polished self-image while claiming to be authentic may result in linguistic strategies of compromise when dealing with context collapse (boyd and Marwick 2011; see also the discussion in Section 4.2. below). Through the interplay of these factors, the drive toward authenticity in the sense of the 'doing approach' (Butler 1988) can be understood as 'doing authenticity' (Georgakopoulou 2016, 2017), that is, in the form of a curated authenticity.

4.2 Usernames as curated authenticity? 
To gain an insight into the choice of online names in the UK, we conducted a questionnaire among British students (Kersten and Lotze 2018, 2020; see also Section 2). These kinds of questionnaires are routinely employed in onomastic studies, since the motivaton behind usernames cannot be tapped into by analysing usernames alone (see e.g., Hagström 2008, 2012; Aleksiejuk 2016a). Participants were asked to provide examples of usernames they created, the platform they were created for and to give a brief explanation as to why this username was chosen. Following a Grounded Theory approach, we clustered the usernames according to the predominant motivations behind the name choice along three continua: a) authenticity and anonymity, b) individualisation and group convergence, and c) phonic and graphic aesthetics. The interpretation of self-naming practices on these continua was driven by the insight that users see the decision between personal authenticity or anonymity on the web not as a dichotomous choice between incorporating their full name or a completely opaque username but rather opted for interesting strategies of compromise. $27 \%$ of the self-naming strategies were based on the principle of anonymity by using appellatives as usernames, 59\% incorporated their full birth names (or parts thereof), while others (14\%) chose strategies that are a compromise between these two strategies (incorporation of middle names or childhood nicknames, for example) that are only meaningful and identifiable for an in-group.

In the international comparison, the results of the Nicknamen International study reflected the different attitudes towards digital safety and authentication practices in online communication, which are at times diametrically opposed. While in the English, Swedish, Croatian, Luxembourgish and Arabic data there was a clear tendency towards authenticity with over half of the respondents $(59 \%)$ stating that they use their birth or legal names (or parts thereof), the Japanese (20\%) and in particular the Chinese (12\%) data differed significantly in this respect. While the results of the UK questionnaire showed that over half of the users follow a guiding principle of openness and authenticity, which has a positive connotation for them, Oberwinkler (2018: 166) cites Orita and Miuri (2011) who state that there is a widespread apprehension towards being identifiable on the internet. The fact that only very few birth names are used on the Weibo platform in China can be related to the political climate and the state surveillance of digital spaces. In addition, names in China are used more dynamically overall, that is, are more flexible for different phases of life and names are routinely translated or adapted when abroad, etc. (see, for Taiwan, Chen 2016; Huang and Ke 2016). Username choice is therefore a culturally dependent act that includes making assumptions about a standard of a) what formally constitutes a name (in the traditional and legal sense) and b) how many characteristics or elements of this a username should contain. 
In contrast to other aspects of online face-work, self-naming practices also have a legal dimension (authentication through the use of a legal name thus authenticating oneself as a legal person), which is evident in the real-name policy of, for example, Facebook that was first introduced in 2018, ${ }^{4}$ and has gained more traction in the light of recent debates about 'fake news'. This in turn is at odds with an individual's wish for the preservation of anonymity. Nevertheless, against the background of 'context collapse' (boyd and Marwick 2011), selfnaming online can only be defined antinomically, since the loss of a clear target audience leads to different strategies employed by different users: consistent use of the birth name in online handles (i.e., self-naming as curated authenticity), consistent use of a pseudonym across different platforms (i.e., self-naming as curated anonymity) or different strategies on different platforms (i.e., self-naming in relation to a $\mathrm{CoP}$ ) as well as a mix of these strategies (i.e., selfnaming in response to media conversion).

Online self-naming practices can therefore only be interpreted taking into account the architecture of social media as a data trading business model and its communication structure (anonymity-authenticity dilemma, context collapse, trans-mediality, media conversion). As a consequence, online face-work must always address two levels: that of general social conventions and those of special group conventions of the corresponding community. Therefore, it must also be defined in two ways: as group-specific face-work in the sense of a curated self, which, in order to be an authentication practice, has to be based on formally existing naming conventions and laws (general social norms) or username conventions that are the result of technological constraints that vary from platform to platform (technological standardization).

\footnotetext{
${ }^{4}$ see e.g., https://www.facebook.com/help/112146705538576.
} 


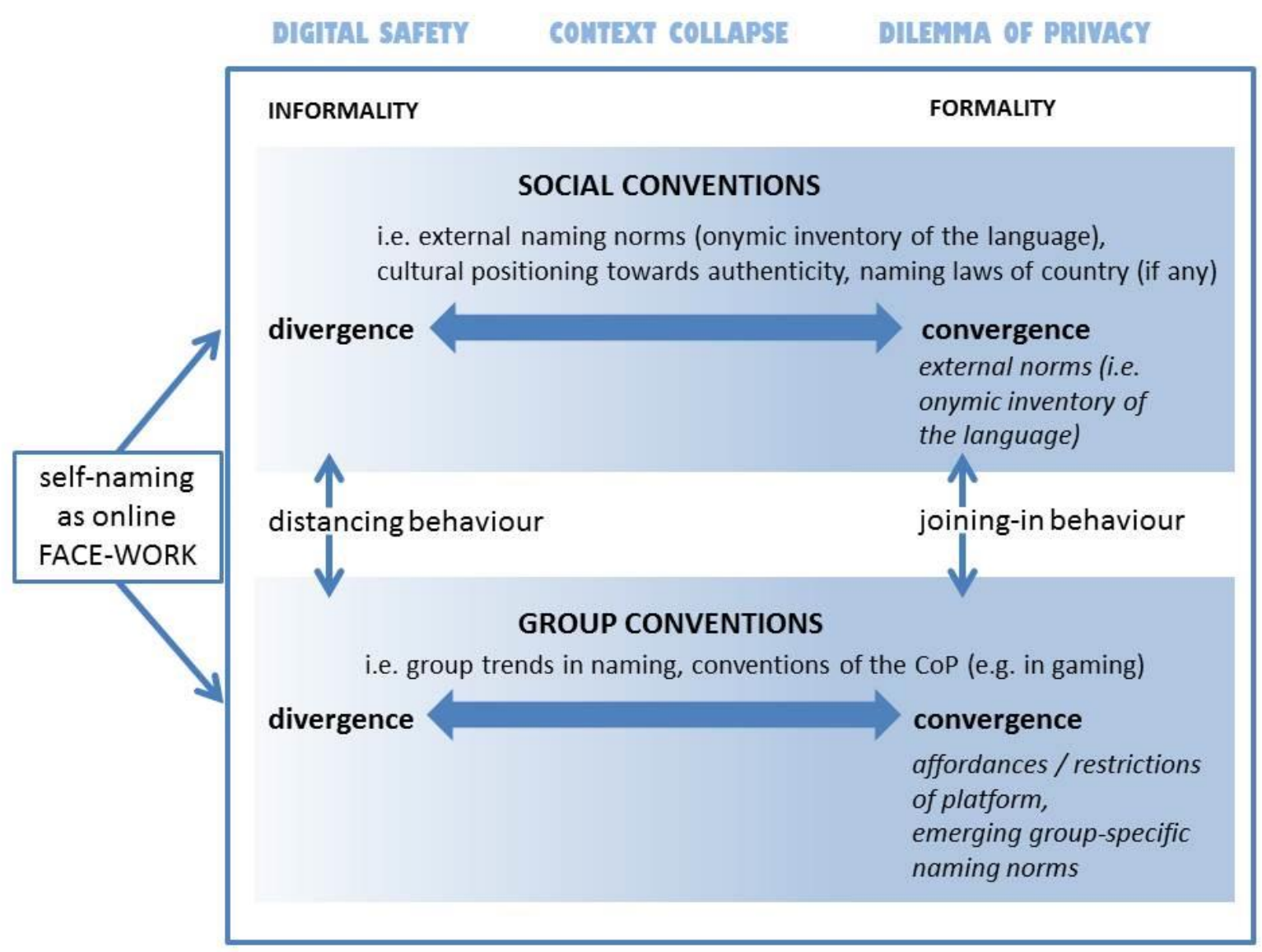

Figure 2. Levels of online face-work

Taking into account these dimensions, emergent variation and change of online self-naming strategies within communities, our data suggest that this should also be thought of diachronically, for example, if in the future changes in these respective communities result in a general standardization of online self-naming.

The individual always has the choice to opt for following or rejecting a convention or to choose a strategy of compromise that simultaneously partially follows and rejects the convention at the same time (bottom half of Figure 2). Aside from this, the options to either follow or reject naming conventions (or a mixture of both) are necessarily on a continuum and can be thought of as a form of positioning of the individual in relation to a specific group or society as a whole (top half of Figure 2).

4.3 Username choice: Identity construction as positioning in relation to a community

In this section we address the micro-perspective on self-naming online as an element of the wider field of identity construction in social groups from a social science point of view. 
While the variables discussed above (context collapse, the dilemma of authenticity versus anonymity) form a framework for online self-naming from a socio-pragmatic perspective, the choice of a username contributes to the construction of identity by positioning the individual in relation to one or more communities. Goffman intended his concept of face-work to be extremely general so that it can be applied to a wide variety of contexts. Using face-work as the overarching umbrella concept, the way face functions manifest can be described in much greater detail, as has been done by a number of scholars (e.g., Bedijs, Held and Maßß 2014). For the following discussion for the context of online self-naming, the principles outlined by Bucholtz and Hall (2005) is used for further systematization in order to be able to classify the interactive construction of identity according to five principles. Identity is defined here as "the social positioning of self and other" (Bucholtz and Hall 2005: 586), while identity is understood to be a discursive construct and therefore inherently linguistic. The theory is closely related to interactional constructivism. Bucholtz and Hall (2005) posit the following basic principles based on interdisciplinary research on identity:

- Emergence: Identity is understood to be the result of an interactive negotiation process and can thus be interpreted in the context of an interactive doing approach ('doing gender', 'doing identity').

- Positionality: Identity is constituted via spatial and temporal variables as studied by traditional ethnography (diatopic and diachronic variation).

- Indexicality: The process of identity construction is indexical, which means that identity is constituted in relation to social groups to which one refers with certain culturally grown linguistic means (labels, style characteristics).

- Relationality: Identity is strengthened by concrete semantic relations such as similarity vs. difference, naturalness vs. artificiality or power vs. impotence constituted, for example, by self-staging.

- Partialness: Because identity is intersubjectively constituted, it is always only partially experienceable, interpretable, etc. and therefore agentivity is fundamentally collaborative.

On the basis of these five principles, the choice of name can also be interpreted as a partial aspect of the identity construction of an individual. As a sociolinguistically relevant practice, name selection can thus also be regarded to be an interactively negotiated process ('doing naming', see also Aldrin 2011). As a consequence, the choice of name often results in a temporal or spatial positioning (fashionable names, regional names). In addition, names index 
social groups (see e.g., Nübling 2017: 313 for a discussion of Charlotte vs. Chantal in Germany). Self-naming practices in particular can be interpreted in relation to certain relevant topoi (e.g., self-staging as authentic by using one's birth or legal name on social media). Finally, choosing a name is a genuinely collaborative, only partially controllable process that draws on given names (legal or birthnames, nicknames, etc.) and self-naming (usernames, pseudonyms).

\section{Self-naming online as an identity-constitutive form of face-work}

In the following section, the motivation of users for choosing a particular username will be discussed. Since usernames are extremely dense and complex semantic units that only become meaningful through their socio-pragmatic contextualization, the main objective is to determine how users present themselves to whom as who using which kind of username? The results of our questionnaire on self-naming practices are presented and interpreted in the framework of Goffman's (1955) face-work approach and the principles of identity construction according to Bucholtz and Hall (2005). For a more detailed discussion of the additonal corpus analysis of 500 British user names regarding morphology, syntax and semantic domains see Kersten and Lotze (2018) and Lotze and Kersten (2020, in press).

\subsection{Results of the questionnaire}

As outlined in Section 2, a questionnaire was distributed among 71 students at a British university in the summer term of 2017 (in addition to the wider corpus study). These students were asked to provide examples of usernames they use, the platform(s) they use them on and their reasons for choosing these usernames; a total of 121 usernames plus comments were collected.

Our results show that usernames were chosen based on a range of criteria which can each be represented as anchors of a spectrum (e.g., anonymization - authentication). Self-naming can thus be interpreted as identity work in reference to the community (see Seargeant and Tagg 2014: 1-20) in relation to certain values (see Relationality, Bucholtz and Hall 2005: 598-599).

After analysing the questionnaire responses using grounded theory (Przyborski and Wohlrab-Sahr 2014: 201), we were able to derive four guiding principles (Helfferich 2014: 561) from the empirical data which the respondents appear to view as relevant for their choice of username: mono-referenciality, self-representation, authentication - anonymization, individualization - group convergence. 


\section{a. Mono-referenciality}

Mono-referenciality is not only enforced by social media platforms as outlined at the end of Section 2 but also distinguishes personal names from appellatives in that names (ideally) refer to a person in a mono-referential manner. This does not exist in the context of the onymic inventory of English, since names such as Jennifer Brown cannot be called mono-referential in the strictest sense, because several people may have this legal name. If the username jennifer_brown has already been assigned, the technology demands maximum discrimination through, for example, the addition of numbers (jennifer_brown1). One of the respondents to our survey explains her username on Instagram, erinmoody $9,{ }^{5}$ which contains a relatively high number, thus: "my name is Erin Moody \& the number 9 was assigned to me because apparently erinmoody $2,3,4,5,6,7,8$ were already taken". While numbering is routinely employed when naming livestock or laboratory animals and leads to a de-individualisation which may very well be desired, the same practice when applied to names for humans is seen to be de-humanizing (cf. Nübling et al. 2015). In usernames, however, numbers are routinely added, in particular to birth names (see Hämäläinen 2013).

\section{b. Self-representation}

Older studies on the Web 1.0 in particular (e.g., Bechar-Israeli 1995) show that users enact a partial identity through their usernames (in the sense of postmodernism, see Keupp et al. 2002). Due to the increasing blurring of online and offline spheres, this aspect lacks relevance in social media (i.e., Web 2.0) and we can only find evidence for this practice in gaming (cf. Kaziaba 2016). What is more important in this context is that users are conscious of underlying conventions and norms dependent on the community context regarding perceived aesthetics of a username as a means of self-presentation within these communities. Consequently, @vintage.e.lnd $d^{6}$ explains her name as follows: "I love clothes (vintage), my first name starts with an 'e' and I'm from London, i.e. 'Idn."”

This principle also depends on the cognitive concept of graphic or phonic aesthetics. In order to devise a creative name in written media, respondents were often influenced by an orality-oriented concept of communication (see Dürscheid 2016). For example, melancholypeach explained their choice of name by stating "I like the flow of it", although the

\footnotetext{
${ }^{5}$ The last name is anonymised here in line with the requirements of the ethics approval.

6 The @-mention is added by Twitter automatically.
} 
name is likely to be written and read more often than spoken out loud. Similarly, Shovelwave states that "it's a cool word."

\section{c. Authentification-anonymisation}

More than half of the 121 usernames (59\%) in our questionnaire data contained the full birth name or parts thereof. The decision to include these is consistently justified by respondents with the fact that their profile can be found more easily by friends and relatives because of it. Some believe that greater transparency in the choice of names is perceived by the community as an indicator of openness and trustworthiness. Authenticity is understood here in relation to its ethical implications and interpreted as a social value. Authentication is therefore an interactive practice in relation to the social group and its values and norms.

Only $27 \%$ of respondents strive for complete anonymity. They mainly choose creative usernames using appellatives, thus retaining obscurity with regard to their referent (pineapplehair, Queen Hippo). A common explanation in this context is that names that are included are nicknames that users were given in the past, for example, during their childhood. For instance, pineapplehair was "my nickname in primary school" and Queen Hippo was "a story we made with my friends, when I was younger." Another reason for anonymization is the (perceived) public audience of the platform (e.g., gaming, YouTube) and the associated desire for digital safety: "don't give my full name on a large platform." The affordances of the platform and the related constraints thus appear to promote the use of various strategies to preserve anonymity on the part of the users.

It is interesting that some of the respondents also opt for a compromise between authentication through onymicity and anonymity through the inclusion of appellatives. For British students, initials, middle names or nicknames bestowed upon them by friends or relatives represent such a compromise (14\%). By using these nicknames only known to a select few, they can be found by members of the in-group but not be easily identified by strangers. For example, @ally_sparham explains their name as follows: “ally was a name given to me by friends in lower school and it's just stuck".

\section{d. Individualisation vs. group-convergence}

The positioning of users in relation to social groups or online communities is another relevant factor (see Tajfel and Turner 1986). One student has chosen the username DARK_eXtreme to

signal that he "was part of a group" on a gaming platform. Boyd and Marwick (2011: 140) call this adaptation to the linguistic conventions of an online community "social convergence." It 
is interesting that the choice of username cannot only be interpreted as a reaction to conventions within an existing group; sometimes the community is constituted through the choice of usernames similar to the function of hashtags (cf. fluid community, Tagg 2015: 160). The respondent who supplied the username majesty belle states that they use this username because it was "associated with a TV show character - so people can find me." Users also tend to follow trends as a cross-community strategy, not only within a particular community, both of which are evident in our data: $x A S 4$ explains their username as follows: " $\mathrm{x}$ was just current at the time." The choice of username can therefore be interpreted as face-work and an authentication practice to signal membership of a particular group with shared interests, that is, a Community of Practice.

\section{Discussion and conclusion}

The face-work concept is abstract enough to also account for the notion of self-naming as a form of curating a self-image online; in the Web 2.0 the first and foremost goal of selfrepresentation is (curated) authenticity. However, face-work was deliberately conceived as a broad concept that subsequently allows for analysis and categorisation of a range of functions and associated communicative strategies. Our next step following Goffman's framework would be to define more precisely which onomastic means relate to which aspect of face. If one attempts to map this concept onto usernames, it turns out that usernames are the result of a naming process and only comprehensible as relational in the sense of "the social positioning of self and other" (Bucholtz and Hall 2005: 586) in relation to CoPs and their corresponding values and norms (e.g. aesthetics, digital safety). The basic principles of online self-naming derived from the results of our questionnaire can largely be integrated into the constructivist model of Bucholtz and Hall (2005), with one exception (mono-referentiality; see below). It is striking that the other three relevant aspects of self-representation, authentication vs. anonymization and individualization vs. group-convergence reported by the respondents all relate to the positioning of the individual towards online communities or the wider public. What these three of our four basic principles of online naming have in common is that they address the qualitative identity of an individual (see Stekeler-Weithofer 1999: 601).

Following Bucholtz and Hall (2005), the qualitative aspects of identity construction through self-naming online can be categorized as shown in Table 1. It is important to mention that it is not the usernames themselves that are categorized in Table 1 but the self-naming 
principles that motivate them and which are complex practices on both the cognitive and interactional level of DMI.

Table 1. Categorization of self-naming online following Bucholtz and Hall (2005)

\begin{tabular}{|c|c|c|}
\hline $\begin{array}{c}\text { Underlying Principle of } \\
\text { Identity Construction }\end{array}$ & Underlying Principle of Online Self-Naming & $\begin{array}{c}\text { Examples from } \\
\text { Our Data (Kersten } \\
\text { and Lotze 2018) }\end{array}$ \\
\hline Eme & $\begin{array}{l}\text { Choosing a name is a dynamic and negotiated process (Aldrin 2011). } \\
\text { In communities, the choice of names is partially commented on and } \\
\text { discussed by the group, which sometimes leads to a change of name } \\
\text { (Bechar-Israeli 1995; Gatson 2011; Lindholm 2013; for gaming: see } \\
\text { Kaziaba 2016). } \\
\text { Relevant factors: } \\
\text { - An internal process of negotiation prior to choosing a username } \\
\text { (which may include discussions with friends, but also introspection } \\
\text { by weighing up different versions) } \\
\text { - External negotiation process within the community }\end{array}$ & $\begin{array}{l}\text { name change from } \\
\text { LailaLaila to Laila } \\
\text { Ellayan (full birth } \\
\text { name) "so people } \\
\text { can find me better" } \\
\text { (user statement) }\end{array}$ \\
\hline Pos & $\begin{array}{l}\text { Choosing a name refers to a diachronic change in internet-based } \\
\text { conventions and thus also to a change in the relevant criteria for } \\
\text { identity work (cf. principle of positionality, Bucholtz and Hall 2005: } \\
\text { 591). In the Web } 1.0 \text { (or early Web 2.0), anonymity and equality were } \\
\text { still closely associated with DMI (see Herring 2001), but nowadays } \\
\text { authenticity is foregrounded and consciously performed } \\
\text { (Georgakopoulou 2015, 2016, 2017). } \\
\text { The choice of name depends on the size and reach of the platform and } \\
\text { the (perceived) audience. } \\
\text { Relevant factors: } \\
\text { - Socio-pragmatic variation and change online (internet } \\
\text { diachronic) } \\
\text { Platform-specific factors (internet diatopic) } \\
\text { Zeitgeist phenomena (diachronic) } \\
\text { Dialectal variants (diatopic) }\end{array}$ & $\begin{array}{l}x A S 4 \text { (use of } x \\
\text { emoticon as an } \\
\text { online trend), } \\
\text { explanation: "x was } \\
\text { current at that time" } \\
\text { (user statement) } \\
\text { wee eddie (use of } \\
\text { dialect to indicate } \\
\text { regional position) }\end{array}$ \\
\hline Indexicality & $\begin{array}{l}\text { Name choice is based on the principle of values and the aesthetic sense } \\
\text { of the community (Bullingham and Vasconcelos 2013; Kaziaba } \\
\text { 2016). Group convergence (following the principle of indexicality) }\end{array}$ & $\begin{array}{l}\text { E300 DSLR } \\
\text { (camera specs) in } \\
\text { expert community }\end{array}$ \\
\hline
\end{tabular}




\begin{tabular}{|c|c|c|}
\hline & $\begin{array}{l}\text { takes place through a curated self-image in the sense of Goffman's } \\
\text { (1955) face-work in reference to group-specific aims and values. } \\
\text { Relevant factors: } \\
\text { - Group trends } \\
\text { - Semiotics / emblems associated with specific scenes }\end{array}$ & $\begin{array}{l}\text { for photography to } \\
\text { authenticate oneself } \\
\text { as a knowledgeable } \\
\text { member of the in- } \\
\text { group } \\
\text { vintage.e.ldn to } \\
\text { indicate } \\
\text { membership of the } \\
\text { community of } \\
\text { vintage } \\
\text { afficionados and } \\
\text { their aesthetics, "I } \\
\text { love vintage } \\
\text { clothes" (user } \\
\text { statement) }\end{array}$ \\
\hline Relationality & $\begin{array}{l}\text { Names are chosen with regard to a range of relevant decision criteria } \\
\text { which are on a cline. Self-naming can be interpreted as identity work } \\
\text { with reference to the community (see Seargeant and Tagg 2014) in } \\
\text { relation to specific values (see Relationality, Bucholtz and Hall 2005: } \\
\text { 598-599). } \\
\text { Relevant factors: } \\
\text { - Anonymity vs. authenticity } \\
\text { - Phonic aesthetics vs. graphemic aesthetics } \\
\text { - etc. }\end{array}$ & $\begin{array}{l}\begin{array}{l}\text { giraffesocks } \\
\text { (anonymity as } \\
\text { guiding principle) }\end{array} \\
\text { Jennifer_Brown } \\
\text { (authenticity as } \\
\text { guiding principle) } \\
\text { jCharlesshow (a } \\
\text { compromise } \\
\text { between } \\
\text { authentification and } \\
\text { anonymity), } \\
\text { "Charles is my } \\
\text { middle name so I } \\
\text { can have moderate } \\
\text { privacy" (user } \\
\text { statement) }\end{array}$ \\
\hline Partialness & $\begin{array}{l}\text { Name choice can only be partially experienced, interpreted and } \\
\text { controlled (principle of partialness, cf. Bucholtz and Hall 2005: 605- } \\
607 \text { ). The name giver or name bearer on the one hand and the person } \\
\text { named by others or the name users on the other have different } \\
\text { communicative agendas and needs. }\end{array}$ & $\begin{array}{l}\text { Pie_95 (childhood } \\
\text { nickname }+ \text { year of } \\
\text { birth, } \quad \text { only } \\
\text { transparent to in- } \\
\text { group) }\end{array}$ \\
\hline
\end{tabular}




\begin{tabular}{|l|l|l|}
\hline & \multicolumn{1}{|l|}{$\begin{array}{l}\text { Jeffacake24 (based } \\
\text { on family nickname } \\
\text { and childhood } \\
\text { interactions, } \\
\text { perceived as being } \\
\text { very unique) }\end{array}$} \\
\hline
\end{tabular}

It is important to note that qualitative identity aspects are soft, relational categories and consequently any attempt at systematization has to remain tentative. In addition, most of the self-naming strategies can be applied to more than one of Bucholtz and Hall's principles (e.g., badcampix (in tech forum), Perseus1, celtic cat, Old Deuteronomy).

The principle of mono-referentiality alone does not refer to the qualitative identity of the individual but to the numerical identity of the individual, that is, the unity with themselves (see Stekeler-Weithofer 1999: 601). The individual is indivisible and threrefore is ONE entity in union with itself (numerical identity). This one individual has different characteristics (qualitative identity). The individual as an indivisible unit is named using a mono-referential name by which they authenticate themselves as a rational agent (Kant, MdS VI 223 [1999]). This aspect has not only a legal component, but also a technological one, particularly on social media where maximum mono-referentiality is enforced. The principle of technologydependent mono-referentiality is thus difficult to integrate into Bucholtz and Hall's (2005) model. This shows the limitations of the constructivist paradigm which cannot be applied to technologies that are by nature deterministic and rely on natural causality but only to their users (for a more detailed discussion of this aspect, see Lotze 2016).

Username choice is therefore influenced by a number of formal and informal conventions which users either choose to align themselves with or from which they diverge. Formality in username conventions is emergent and highly context-dependent while at the same time it also has the possibility to lead to a widely adopted formal standard.

\section{Acknowledgements}

We would like to thank the editors of this special issue as well as two anonymous reviewers for their feedback on an earlier draft of this paper. Thank you also to Joanne McDowell for the fruitful discussions on the terminology around group convergence and divergence. 


\section{References}

Ainiala, Terhi, and Jan-Ola Östman (eds). 2017. Socio-Onomastics: The Pragmatics of Names. Amsterdam: John Benjamins.

Aldrin, Emilia. 2011. "Choosing a name = Choosing identity? Towards a theoretical framework." In Proceedings Els noms en la vida quotidiana: Actes del XXIV Congrés Internacional d'ICOS sobre Ciències. Onomàstiques [Names in daily life : Proceedings of the XXIV ICOS International Congress of Onomastic Sciences], ed. by Joan Tort i Donada, and Montserrat Montagut i Montagut, 392-401. Barcelona: Generalitat de Catalunya.

Aldrin, Emilia. 2019. "Naming, identity, and social positioning in teenagers' everyday mobile phone interaction.” Names 67: 30-39. https://doi.org/10.1080/00277738.2017.1415523

Aleksiejuk, Katarzyna. 2016a. "Internet personal naming practices and trends in scholarly approaches.” In Names and Naming: People, Places, Perceptions and Power, ed. by Guy Puzey, and Laura Kostanski, 5-17. Bristol: Multilingual Matters.

Aleksiejuk, Katarzyna. 2016b. "Pseudonyms." In The Oxford Handbook of Names and Naming, ed. by Carole Hough, 438-452. Oxford: Oxford University Press.

Androutsopoulous, Jannis K. 2007. "Neue Medien - neue Schriftlichkeit? [New Media - New Literacies?]" Mitteilungen des Deutschen Germanistenverbandes 54(1): 72-97.

Androutsopoulos, Jannis K. 2015. "Zuschauer-Engagement auf Twitter: Handlungskategorien der rezeptionsbegleitenden Kommunikation am Beispiel von \#tatort [Audience Engagement on Twitter: Categories of language use when communicating while watching TV using the example of \#tatort]." Zeitschrift für Angewandte Linguistik 62(1): 23-59.

Barton, David, and Carmen Lee. 2013. Language Online: Investigating Digital Texts and Practices. Abingdon: Routledge.

Bechar-Israeli, Haya. 1995. "From <Bonehead> to <cLoNehEAd>: Nicknames, play, and identity on Internet Relay Chat." Journal of Computer-Mediated Communication 1(2): n.p. https://doi.org/10.1111/j.1083-6101.1995.tb00325.x

Bedijs, Kristina, Gudrun Held, and Christiane Maßß. 2014. "Introduction: Face work and social media." In Face Work and Social Media, ed. by Kristina Bedijs, Gudrun Held, and Christiane Maaß, 9-28. Münster: Lit-Verlag.

Beißwenger, Michael, and Steffen Pappert. 2019. "Face work mit Emojis. Was linguistische Analysen zum Verständnis sprachlichen Handelns in digitalen Lernumgebungen beitragen können [Face work with emojis. What linguistic analyses can contribute to the understanding of language use in digital lerning environments]." In Soziale Medien in Schule und Hochschule: Linguistische, sprach- und mediendidaktische Perspektiven [Social Media in School and Higher Education: Linguistic, language and media didactic perspectives], ed. by Michael Beißwenger, and Matthias Knopp, 101-143. Berlin: Peter Lang. 
Bonner, Mehera. 2020. "Kate Middleton and Prince William change their Instagram name for first time in 5 years: I like this so much better." Cosmopolitan. https://www.cosmopolitan.com/entertainment/celebs/a32610717/kate-middleton-prince-williamchange-instagram-name/ (accessed 20 May 2020).

boyd, danah, and Alice Marwick. 2011. 'Social privacy in networked publics: Teens' attitudes, practices and strategies." Presentation at Decade in Internet Time: Symposium on the Dynamics of the Internet and Society, September 2011, https://papers.ssrn.com/sol3/papers.cfm?abstract_id=1925128 (accessed 27 November 2020).

Bucholtz, Mary, and Kira Hall. 2005. "Identity and interaction: A sociocultural linguistic approach." Discourse Studies 7(4-5): 585-614.

Bullingham, Liam, and Ana C. Vasconcelos. 2013. “"The presentation of self in the online world': Goffman and the study of online identities." Journal of Information Science 39(1):101-112. https://doi.org/10.1177/0165551512470051

Butler, Judith. 1988. "Performative acts and gender constitution: An essay in phenomenology and feminist theory." Theatre Journal 40(4): 519-531.

Chen, Yi-An Jason. 2016. "English name transition from Taiwan to the United States: A case study of Taiwanese international students." International Journal of Applied Linguistics \& English Literature 5(4): 58-64.

De Hoyos, Brandon. 2020. "How to create the perfect screen/username." Lifewire.com https://www.lifewire.com/create-perfect-screen-name-1949903 (accessed 27 November 2020).

Del-Teso-Craviotto, Marisol. 2008. "Gender and sexual identity authentication in language use: The case of chat rooms.” Discourse Studies 10(2): 251-270. https://doi.org/10.1177/1461445607087011

Dürscheid, Christa. 2016. "Nähe, Distanz und neue Medien [Immediacy, distance and new media]." In Zur Karriere von 'Nähe und Distanz': Rezeption und Diskussion des Koch-Oesterreicher-Modells [On the career of 'immediacy and distance': Reception and discussion of the model by Koch-Oesterreicher] , ed. by Helmuth Feilke, and Mathilde Henning, 352-385. Berlin: Walter de Gruyter.

Gatson, Sarah N. 2011. "Self-naming practices on the internet: Identity, authenticity, and community." Cultural Studies <-> Critical Methodologies 11(3): 224-235.

Georgakopoulou, Alexandra. 2016. "From narrating the self to posting self(ies): A small stories approach to selfies." Open Linguistics 1: 300-317.

Georgakopoulou, Alexandra. 2017. "Sharing the moment as small stories: The interplay between practices $\&$ affordances in the social media-curation of lives." Narrative Inquiry 27: 311-333.

Goffman, Erving. 1955. "On face-work: An analysis of ritual elements in social interaction." Psychiatry 18(3): 213-231. https://doi.org/10.1080/00332747.1955.11023008

Graham, Lindsay T., and Samuel D. Gosling. 2012. "Impressions of World of Warcraft players' personalities based on their usernames: Interobserver consensus but no accuracy." Journal of Research in Personality 46(5): 599-603. 
Guenther, Katja M. 2009. "The politics of names: Rethinking the methodological and ethical significance of naming people, organizations, and places." Qualitative Research 9(4): 411-421. https://doi.org/10.1177/1468794109337872

Hagström, Charlotte. 2008. "Playing with names: Gaming and naming in the World of Warcraft." In Digital Culture, Play, and Identity: A World of Warcraft Reader, ed. by Hilde Corneliussen, and Jill Walker Rettberg, 265-285. Cambridge, Mass.: The MIT Press.

Hagström, Charlotte. 2012. "Naming me, naming you: Personal names, online signatures and cultural meaning." Oslo Studies in Language 4(3): 81-93.

Hämäläinen, Lasse. 2013. "User names in the online gaming community Playforia." In Names in the Economy: Cultural Prospects, ed. by Paula Sjöblom, Terhi Ainiala, and Ulla Hakala, 214-228. Newcastle upon Tyne: Cambridge Scholars Publishing.

Hanks, Patrick, Kate Hardcastle, and Flavia Hodges. 2006. A Dictionary of First Names. Oxford: Oxford University Press.

Hassa, Samira. 2012. "Projecting, exposing, revealing self in the digital world: Usernames as a social practice in a Moroccan chatroom.” Names 60(4): 201-209. https://doi.org/10.1179/0027773812Z.00000000031

Heisler, Jennifer M., and Scott L. Crabill. 2006. "Who are 'stinkybug' and 'Packerfan4'? Email pseudonyms and participants' perceptions of demography, productivity, and personality." Journal of ComputerMediated Communication 12(1): 114-135.

Helfferich, Cornelia. 2014. "Leitfaden- und Experteninterviews. [Semi-structured and expert interviews]" In Handbuch Methoden der empirischen Sozialforschung [The Handbook of Empiricial Research Methods in the Social Sciences], ed. by Nina Baur, and Jörg Blasius, 559-574. Wiesbaden: Springer.

Herring, Susan C. 2001. “Computer-mediated discourse." In The Handbook of Discourse Analysis, ed. by Deborah Schiffrin, Deborah Tannen, and Heidi E. Hamilton, 612-634. Malden: Blackwell.

Huang, Chiu-Yen, and I-Chung Ke. 2016. "Parents' perspectives on adopting English names in Taiwan." Journal of Multilingual and Multicultural Development 37(8): 849-861.

Kapidzic, Sanja, and Susan C. Herring. 2011. "Gender, communication, and self-presentation in teen chatrooms revisited: Have patterns changed?" Journal of Computer-Mediated Communication 17(1): 39-59. https://doi.org/10.1111/j.1083-6101.2011.01561.x

Kant, Immanuel. 1999. Grundlegung zur Metaphysik der Sitten [Groundwork of the Metaphysics of Morals], ed. by Bernd von Kraft, and Dieter Schönecker. Hamburg: Meiner.

Kaziaba, Viktoria. 2016. "Nicknamen in der Netzkommunikation [Nicknames in online communication]." Der Deutschunterricht 1: 24-29.

Kelley, James B. 2012. "Gay naming in online gaming." Names 60(4): 193-200. https://doi.org/10.1179/0027773812Z.00000000030.

Kersten, Saskia, and Netaya Lotze. 2018. "Englisch [English].” In Nicknamen international: Zur Namenwahl in sozialen Medien in 14 Sprachen [International Nicknames: On name choice on social media in 14 languages], ed. by Peter Schlobinski, and Torsten Siever, 101-124. Berlin: Peter Lang. 
Kersten, Saskia, and Netaya Lotze. 2020. "Creating a self-image: Face-work and identity construction online.” Journal for Media Linguistics 2(2): 123-156. https://doi.org/10.21248/jfml.2019.20

Keupp, Heiner, Thomas Ahbe, Wolfgang Gmür, Renate Höfer, Beate Mitzscherlich, Wolfgang Kraus, and Florian Sraus. 2002. Identitätskonstruktionen: Das Patchwork der Identitäten in der Spätmoderne [Identity Constructions: The patchwork of identities in the late modern period]. Reinbeck: Rowohlt.

Kooti, Farshad, Haeryun Yang, Meeyoung Cha, Krishna Gummadi, and Winter Mason. 2012. "The emergence of conventions in online social networks." In Proceedings of the Sixth International AAAI Conference on Weblogs and Social Media, 194-201.

Lange, Benjamin P., Maximilian T. P. von Andrian-Werburg, Dorothea C. Adler, and Eugen Zaretsky. 2019. "The name is the game: Nicknames as predictors of personality and mating strategy in online dating." Frontiers in Communication 4(3): n.p. https://doi.org/10.3389/fcomm.2019.00003

Lave, Jean, and Etienne Wenger. 1991. Situated Learning: Legitimate Peripheral Participation. Cambridge: Cambridge University Press.

Lev, Eimi, and Anat Lewinsky. 2004. "The presentation of self in online life: The importance of nicknames in online environments." Conference presentation, Internet Research 5.0: Ubiquity?, University of Sussex, 19-22 September 2004.

Lindholm, Loukia. 2013. "The maxims of online nicknames." In Pragmatics of Computer-Mediated Communication, ed. by Susan C. Herring, Dieter Stein, and Tuija Virtanen, 427-461. Berlin: Wlater de Gruyter.

Lotze, Netaya. 2016. Chatbots: Eine linguistische Analyse [Chatbots: A linguistic analysis]. Hamburg: Peter Lang.

Lotze, Netaya, and Saskia Kersten. in press. "Nicknamen zwischen Anonymität und Wiedererkennungswert [Nicknames between anonymity and recognisability]." Österreichische Namenforschung (Special Issue Namen Digital [Digital Names] 48:79-122.

Lotze, Netaya, and Saskia Kersten. under review. "Methoden der Internet-Onomastik - Zur kontrastiven Analyse von Nicknamen [Methods in Internet Onomastics - On the contrastive analysis of nicknames]." In Methoden kontrastiver Medienlinguistik [Methods in constrastive media linguistics], ed. by Susanne Tienke, Stefan Hauser, Hartmut Lenk, and Martin Luginbühl.

Luhmann, Niklas. 1984. Soziale Systeme: Grundriß einer allgemeinen Theorie [Social Systems]. Frankfurt am Main: Suhrkamp.

Martin, Marcienne. 2013. "Pseudonyms on the internet: A hidden discourse." In Names and Naming: Onomastics in Contemporary Public Space (Proceedings of the Second International Conference on Onomastics), ed. by Oliviu Felecan, 774-792. Cluj-Napoca: Editura Mega/Editura Argonaut.

Marx, Konstanze, and Georg Weidacher. 2014. Internetlinguistik: Ein Lehr- und Arbeitsbuch [Internet Linguistics: A coursebook]. Tübingen: Narr.

Marx, Konstanze, and Netaya Lotze. 2019. "Jugendsprache und Medien [Youth Language and Media]." In Jugendsprache - Eine Einführung [Youth Language - An introduction], ed. by Nils Bahlo, Tabea 
Becker, Zeynep Kalkavan-Aydin, Netaya Lotze, Konstanze Marx, Christian Schwarz, and Yazgül Simsek, 79-119. Berlin: Metzler.

Morgan, Chloe. 2020. "Prince William and Kate Middleton change the display name on their social media accounts to 'The Duke and Duchess of Cambridge' - And fans say it 'feels more personal' than 'Kensington Palace'." Mail Online. https://www.dailymail.co.uk/femail/article-8339491/PrinceWilliam-Kate-Middleton-change-display-names-social-media-accounts.html (accessed 20 May 2020). Nübling, Damaris. 2017. "Beziehung überschreibt Geschlecht: Zu einem Genderindex von Ruf- und von Kosenamen [Relationship overrides gender: On the gender of given names and nicknames].” In Sprache und Beziehung [Language and relation], ed. by Angelika Linke, and Juliane Schröter, 99-118. Berlin: Walter de Gruyter.

Nübling, Damaris, Fabian Fahlbusch, and Rita Heuser. 2015. Namen: Eine Einführung in die Onomastik [Names: An introduction to onomastics] (2nd edn.). Tübingen: Narr Francke Attempto Verlag.

Obwerwinkler, Michaela. 2018. "Japanisch [Japanese]." In Nicknamen international: Zur Namenwahl in sozialen Medien in 14 Sprachen [International Nicknames: On name choice on social media in 14 languages], ed. by Peter Schlobinski, and Torsten Siever, 161-190. Frankfurt am Main: Lang.

Olivier, Jako. 2014. "Twitter usernames: Exploring the nature of online South African nicknames." Nomina Africana 28(2): 51-74.

Pickering, Michael J., and Simon Garrod. 2004. "Towards a mechanistic psychology of dialogue." Behavioural and Brain Sciences 27: 169-225.

Przyborski, Aglaja, and Monika Wohlrab-Sahr. 2014. Qualitative Sozialforschung: Ein Arbeitsbuch [Qualitative Social Science Research: A coursebook]. München: Oldenbourg.

Raátz, Judit. 2011. "Nick as self attributed name.” Nouvelle Revue d'onmastique 53: 183-211.

Rodino, Michelle. 1997. "Breaking out of binaries: Reconceptualizing gender and its relationship to language in computer-mediated communication." Journal of Computer-Mediated Communication 3(3): n.p. https://doi.org/10.1111/j.1083-6101.1997.tb00074.x

Scheidt, Lois. 2001. Avatars and Nicknames in Adolescent Chat Spaces. https://www.academia.edu/2958619/Avatars_and_nicknames_in_adolescent_chat_spaces (accessed 27 November 2020).

Schlobinski, Peter. 2012. "Sprache und Kommunikation im digitalen Zeitalter [Language and Communication in the Digital Age]." https://www.mediensprache.net/de/essays/6/ (accessed 27 November 2020).

Schlobinski, Peter, and Torsten Siever (eds.). 2018a. Nicknamen international: Zur Namenwahl in sozialen Medien in 14 Sprachen [International Nicknames: On name choice on social media in 14 languages]. Berlin: Peter Lang.

Schlobinski, Peter, and Torsten Siever. 2018b. "Einleitung [Introduction]." In Nicknamen international: Zur Namenwahl in sozialen Medien in 14 Sprachen [International Nicknames: On name choice on social media in 14 languages], ed. by Peter Schlobinski, and Torsten Siever, 9-27. Berlin: Peter Lang. 
Seargeant, Philip, and Caroline Tagg. 2014. "Introduction: The language of social media." In The Language of Social Media: Identity and Community on the Internet, ed. by Philipp Seargeant, and Caroline Tagg, 1-20. Basingstoke: Palgrave Macmillan.

Shulman, David. 2017. The Presentation of Self in Contemporary Social Life. Los Angeles: Sage.

Stekeler-Weithofer, Pirin. 1999. "Identifizierung/Unterscheidung." In Enzyklopädie Philosophie: Drei Bände im Schuber und eine CD-ROM [Encyclopedia Philosophy: Three volumes and a CD-ROM], ed. by Hans Jörg Sandkühler et al., 601-603. Hamburg: Meiner.

Stommel, Wyke. 2007. "Mein Nick bin ich! Nicknames in a German forum on eating disorders." Journal of Computer-Mediated Communication 13(1): 141-162. https://doi.org/10.1111/j.10836101.2007.00390.x

Subrahmanyam, Kaveri, Patricia M. Greenfield, and Brendesha Tynes. 2004. "Constructing sexuality and identity in an online teen chat room." Journal of Applied Developmental Psychology 25(6): 651-666. https://doi.org/10.1016/j.appdev.2004.09.007

Tagg, Caroline. 2015. Exploring Digital Communication: Language in Action. Abingdon: Routledge.

Tahiri, Naima. 2018. "Arabisch (marrokanisch). [Morrocan Arabic]" In Nicknamen international: Zur Namenwahl in sozialen Medien in 14 Sprachen [International Nicknames: On name choice on social media in 14 languages], ed. by Peter Schlobinski, and Torsten Siever, 30-56. Berlin: Peter Lang.

Tajfel, Henri, and John C. Turner. 1986. "The social identity theory of intergroup behavior." In Psychology of Intergroup Relations, ed. by Stephen Worchel, and William G. Austin, 7-24. Chicago, IL: NelsonHall.

Zhu, Jia, and Yao Zhang. 2018. "Chinesisch [Chinese]." In Nicknamen international: Zur Namenwahl in sozialen Medien in 14 Sprachen [International Nicknames: On name choice on social media in 14 languages], ed. by Peter Schlobinski, and Torsten Siever, 57-76. Berlin: Peter Lang.

\section{Address for correspondence}

Saskia Kersten

University of Hertfordshire

School of Humanities

Hatfield

Hertfordshire

AL10 9AB

United Kingdom

s.kersten@herts.ac.uk

\section{Biographical notes}

Dr Saskia Kersten is Senior Lecturer in English Language \& Linguistics at the University of Hertfordshire, UK. Saskia completed her doctorate on vocabulary acquisition in the EFL primary school classroom at the 
University of Hildesheim, Germany, in 2009. Her research focusses on digitally-mediated communication, the role of formulaic language in second language development and the use of corpora in interdisciplinary research.

Dr Netaya Lotze is a linguist and senior researcher specializing in new media at the University of Münster, Germany, currently holding a position as substitute professor at the University of Hamburg, Germany. After obtaining a degree in German Studies and Philosophy, she completed her $\mathrm{PhD}$ on human interaction with artificial intelligence in 2014. 